\title{
Diversity and its Impact on Organizational Performance: The Influence of Diversity Constructions on Expectations and Outcomes
}

\author{
Starlene M. Simons(I) and Kimberly N. Rowland
}

\begin{abstract}
Diversity and diverse integration viewpoints into organizations are pertinent in a world of shifting demographic patterns and work practices. The challenge of implementing diversity in organizations is increased by the lack of clarification regarding the difference between functional and social diversity in the literature, which results in a lack of differentiation in organizational policies. This lack of clarification is reflected in theoretical research regarding diversity in the workforce and in pragmatic research regarding diversity. This research thematically analyzes the definitions of diversity in management literature to determine whether this differentiation is made in theoretical or practical discussions of diversity management.
\end{abstract}

Keywords: Diversity; social diversity; functional diversity; innovation, performance; diversity management.

(I) Graduate School of Management and Technology, University of Maryland University College, 350I University Boulevard East,Adelphi, MD 20783-808I / Phone: (240) 245-3758, E-mail:Starlenejo@aol.com 


\section{Introduction}

The modern workforce is far more varied in its composition than it has been previously, due to demographic factors, such as immigration and economic factors like globalization (Christian, Porter and Moffitt, 2006). According to Christian, Porter and Moffitt (2006), the minority workforce in the United States is expected to rise from $16.5 \%$ in 2000 to an estimated $25 \%$ in 2050. In keeping with this increasing level of diversity inherent in the workforce, diversity management has been increasingly a matter of academic and practical interest, and the rate at which diversity management programs have been adopted has been steadily growing. However, this relationship has not been carefree, and a number of companies have reported problems with or outright failure of their diversity management approaches (Christian, Porter and Moffitt, 2006).

One of the challenges in implementing diversity in the organization is the confusion between functional diversity and types of non-functional diversity. Functional diversity, or diversity that leads to more effective function or innovation (Bunderson and Sutcliffe, 2002), is often the form of diversity intended in common workplace statements such as "we need to focus on diversity," or "diversity is something we strive for." However, in practice there are many forms of diversity that can be encountered in organizations, not all of which are related to improving organizational effectiveness, and some of which may be harmful. Many of these forms of diversity have been termed social diversity (Bunderson and Sutcliffe, 2002). What clear distinction can be made between functional diversity and social diversity in the organization, and how can this clear distinction be made?

\section{Statement of Purpose}

The purpose of this research is to examine the definitions offered within the literature on diversity and explore the various constructions of diversity that are extant. It will consider how the definitions of diversity offered in the literature help or impede the formation of effective organizational innovation if applied. This paper uses a selection of case studies using a small number of previously published papers to address achieve these purposes. Ultimately, the goal of this paper is to identify where areas of improvement could be made in the existing literature regarding the discussion of diversity in order to improve its impact on the expected organizational outcomes.

\section{Key Literature}

Key literature has been reviewed to provide a foundation for the research discussion. This literature is used to define the concepts that will be used and provide a foundation for consideration of how well the pragmatic literature on the subject defines the concepts at hand. The theoretical foundation of the research comes from the sociological concept of the social network, while key foundational texts include research on two different perspectives on social networks, the information and decision making perspective and the social diversity perspective.

\section{Understanding Diversity Definitions}

A theoretical foundation for workplace diversity can be found in research regarding social networks. One principle of social networks is that they are homophilous and tend to be homogenous (McPherson, Smith-Lovin, and Cook, 200I). That is, individuals often prefer to form social relationships with those whom they share significant socio-demographic and other personal characteristics. This tendency is prevalent throughout social interaction groups in many societies, including familial, marriage, work, and other personal relationships (McPherson, Smith-Lovin, and Cook, 200I). This does not indicate that dissimilar individuals never form social ties, but social ties formed between dissimilar individuals tend to dissolve faster and be more fragile than those that form between similar individuals. However, this does not indicate that homophilous connections are most appropriate for all situations. As McPherson, SmithLovin, and Cook (200I) note, recent research in social networks has shown that in order to promote change within this network, even in cases where there is a clear impetus for change, the use of external perspectives is often demanded because of the similarity in outlook between individuals. Furthermore, another important element of the organizational perspective on diversity is the issue of the organization itself, which serves as a point of connection for individuals despite any differences in their socio-demographic or other characteristics. In fact, in studies of entrepreneurs, female entrepreneurs could increase their access to capital and other resources such as business expertise by joining male-dominated business groups. In this case, the similarity posed by co-membership in the entrepreneurial organization overcome gender-based diversity differences to improve outcomes for the entrepreneurs (McPherson, Smith- 
Lovin, and Cook, 200I). As noted by McPherson, SmithLovin, and Cook (200I), there was insufficient research on issues of social group dynamics, which would be the area where this theory would be reflected in the current research. Thus, even this highly theoretical perspective is missing a significant element of research understanding.

\section{Classification of Diversity}

There have been a number of types of diversity classification proposed in the literature, not all of which are defined consistently. A majority of these diversity characteristic classifications are based on perceptionand are dichotomous in nature. Some of the classifications that can be identified in the literature include readily detectable/less observable, surface-level/deep-level, highly job-related/less jobrelated, task-related/relations-oriented, and role-related/ inherent dimensions (Christian, Porter and Moffitt, 2006). However, the majority of these classifications can be broken down into two perspectives, the information and decision making perspective and the social organization perspective (Christian, Porter and Moffitt, 2006).

\section{Information and decision making perspective.}

The information and decision making perspective is presented by Cox and Blake (1991), who proposed this perspective as a theoretical means of understanding the link between organizational diversity and organizational effectiveness. They observed that up to that time, the literatureavailablehadassertedalinkbetweenorganizational diversity and organizational effectiveness (and some studies had demonstrated this link using field studies of empirical findings) (Cox and Blake, 1991). However, none of these studies had actually proposed or tested a causal mechanism associated with this link, instead leaving this issue open to interpretation. The information processing and decision making perspective effectively encapsulates the cognitive resource diversity theory, which posits that the cognitive resources of each team member contribute to the overall success of the team; therefore, a diversity of the cognitive resources promotes creativity and decision making capacity (Horwitz, 2005). There is evidence from a wide variety of team types, including flight crews and virtual teams, support this framework of understanding diversity in teams (Guzzo and Dickson, 1996). However, this framework is often only explored in the team context and does not move beyond the team into the organization as a whole (Van Knippenberg and Schippers, 2007).
Coxand Blake (199I) proposed that cultural diversity would impact six direct aspects of organizational effectiveness, including the capability to attract human resources, cost, the issues of innovation, creativity, and problem solving, the marketing advantages of a diverse workforce, and organizational flexibility. These six elements were reviewed in terms of the major literature of the period. For the information and decision making perspective, the most relevant domains studied by the authors were innovation and creativity, problem solving capacity, and organizational flexibility. The authors' argument regarding these three perspectives can be summarized as follows. Creativity and innovation can be aided by "diversity of perspectives and less emphasis on conformity to the norms of the past" (Cox and Blake, 199I, p. 47), which will increase the ability of the organization to create and innovate. The problem-solving argument holds that better decisions would be produced through more perspectives inherent in heterogeneous problem solving groups (Cox and Blake, 1991). Finally, the flexibility argument indicates that multicultural management practices would result in changes that meant "that the system will become less determinant, less standardized, and therefore more fluid" (Cox and Blake, 1991, p. 47). These changes are likely to increase the ability of the organization to react to changing environments.

These three arguments of diversity form the core of what is defined as functional diversity within this discussion. However, in common with later discussions of this type of diversity, the authors do not offer a specific definition of diversity that identifies the forms of diversity likely to be affected by this mechanism, although the discussion touches on issues of bilingualism and gender diversity (Cox and Blake, 1991). This can be seen to be a persistent theme throughout the literature, with many of the studies that were reviewed not clarifying what types of diversity were reflected in their studies.

\section{Social organization perspective}

An alternative perspective on the definition of diversity is that of the social organization perspective. This definition is based in the similarity attraction paradigm (Horwitz, 2005). The similarity attraction paradigm is based in the idea of social homophily as discussed above. That is, individuals that are more similar will be able to work together more effectively (McPherson, Smith-Lovin, and Cook, 200I). The social organization perspective focuses on social 
categories (including age, race-ethnicity, and so on) as a means of accessing external networks as well as a source of increasing conflict between individuals within the social group (Horwitz, 2005). However, the social organization perspective also recognizes a significant source of conflict and loss of efficiency within organizations related to the alignment of individuals along social identity lines.

In particular, alignment along social identity lines can cause considerable conflict between social groups since this identity-based alignment replicates tensions within the organization based on differing social treatment of groups (Schneider and Northcraft, 1999). This social identity causes what the authors term "temporal gaps and collective fences" (Schneider and Northcraft, 1999, p. 1445), which creates conditions under which functional diversity becomes less important. This can also create gaps in individual and managerial participation in diversity, which ultimately can cause problems in the social foundation of the organization (Schneider and Northcraft, 1999). This effect is not consistent as significant amounts of other research has determined that social identity diversity can cause positive effects in teams as well as negative effects if well-managed, implying that leadership plays a moderating role in social identity diversity relationships (Christian, Porter and Moffitt, 2006; Horwitz, 2005).

There is other research that also suggests that leadership plays an important role in the outcomes of team management. The full body of this research is too complex to review, given that leadership is one of the most important and high-volume areas of management research. However, a recent review has examined the role of leadership in the organization and its effects on innovation (Friedrich, et al., 2010). Interestingly, the study conducted by Friedrich, et al. (2010) found that using a single catch-all construct for the central idea of innovation did not have the most effective results. Instead, the use of multiple constructs that reflected innovation at the individual, team, and organizational level as well as in terms of simple and complex innovations was more effective in identifying the effects of innovation. The study used multiple constructs of diversity, focusing specifically on functional diversity at the group level, and found that functional diversity of the group was directly related to the outcomes of the innovation process and leadership. Thus, leadership and the potential for a mediating or moderating role between diversity and innovation is well founded. However, there is a need to consider the potential for leadership in studies that have not included this factor, as it may be an explanatory factor in the variation of studies regarding diversity.
Furthermore, research has shown that diversity of values, rather than diversity of demographic characteristics, was more likely to be at the heart of negative effects on team performance (Van Knippenberg and Schippers, 2007). This research is interesting because it does imply that studies that find differences in diversity outcomes based on demographics are actually identifying a rough proxy based on some demographic characteristics. However, there are also differences that can be found in the activation of social identity structures based on the organizational environment. In particular, organizational factors including organizational focus on social identity may affect the identification of individuals along these lines. Other factors that are likely to affect the outcomes of this identification include cognition, behavior, and affect of the team members (including both the identity-bearer and those around them) (Brickson, 2000). Put simply, Brickson's theoretical model is based on the assumption that the outcomes of social identity diversity are likely to be dependent on the reactions to the individuals with these diverse social identities. This posits that an underlying values-based diversity issue rather than the superficial social diversity issue is more likely to be problematic given the outcomes.

\section{Perspective integration}

The two models of diversity proposed above have a clear internal conflict, which makes them difficult to resolve in concrete terms. The social diversity perspective holds that according to the similarity attraction paradigm, those that are more similar will be more willing to work together, increasing efficiency. On the other hand, the information processing perspective holds that, according to the cognitive diversity theory, a multiplicity of viewpoints will result in better decision making skills and creativity (Horwitz, 2005). Horwitz identified a framework for integration of these two perspectives that could help to identify the characteristic conditions under which these features may be accurate. Critically, this model clearly differentiates between jobrelated diversity, or what might be termed functional diversity characteristics, and bio-demographic diversity, which does not necessarily have a direct bearing on the job outcomes. Horwitz also noted a number of moderating factors that reflect on the outcomes of team performance, which could help to determine the differentiated outcomes that are seen within the literature. Thus, this integrated model is extremely useful for understanding the differences that may be seen in findings regarding diversity. However, even among the different characteristics identified, Horwitz identified a number of different findings regarding diversity depending on the perspective in use by the authors. 
Horwitz also noted that all of the diversity characteristics studied had mixed and inconclusive findings regarding their relative positive or negative effects on team performance. Thus, even in this most clearly defined model, a lack of consistency in the literature does not allow for clarity of definition. This integration of the models is also supported by the empirical findings, which indicate that neither functional nor social diversity has an indisputably positive or negative relationship on the outcomes of team performance. This is not to state that diversity is not at all related to performance, but that the evidence for these findings conflict in terms of the effects and degree seen. Instead, studies have found mixed effects for both of these forms of diversity (Van Knippenberg and Schippers, 2007). Furthermore, the integration of the two models is supported by arguments that indicate that both functional and social diversity is associated with information processing and social categorization. For example, a university degree has both social categorization implications (in terms of social class) and information processing (in terms of training in critical thinking and problem solving). Thus, a definition of diversity that immediately categorizes one form of diversity as positive and one form as negative is not supported by the literature findings, but it is important to have a clear understanding of the types of diversity being examined.

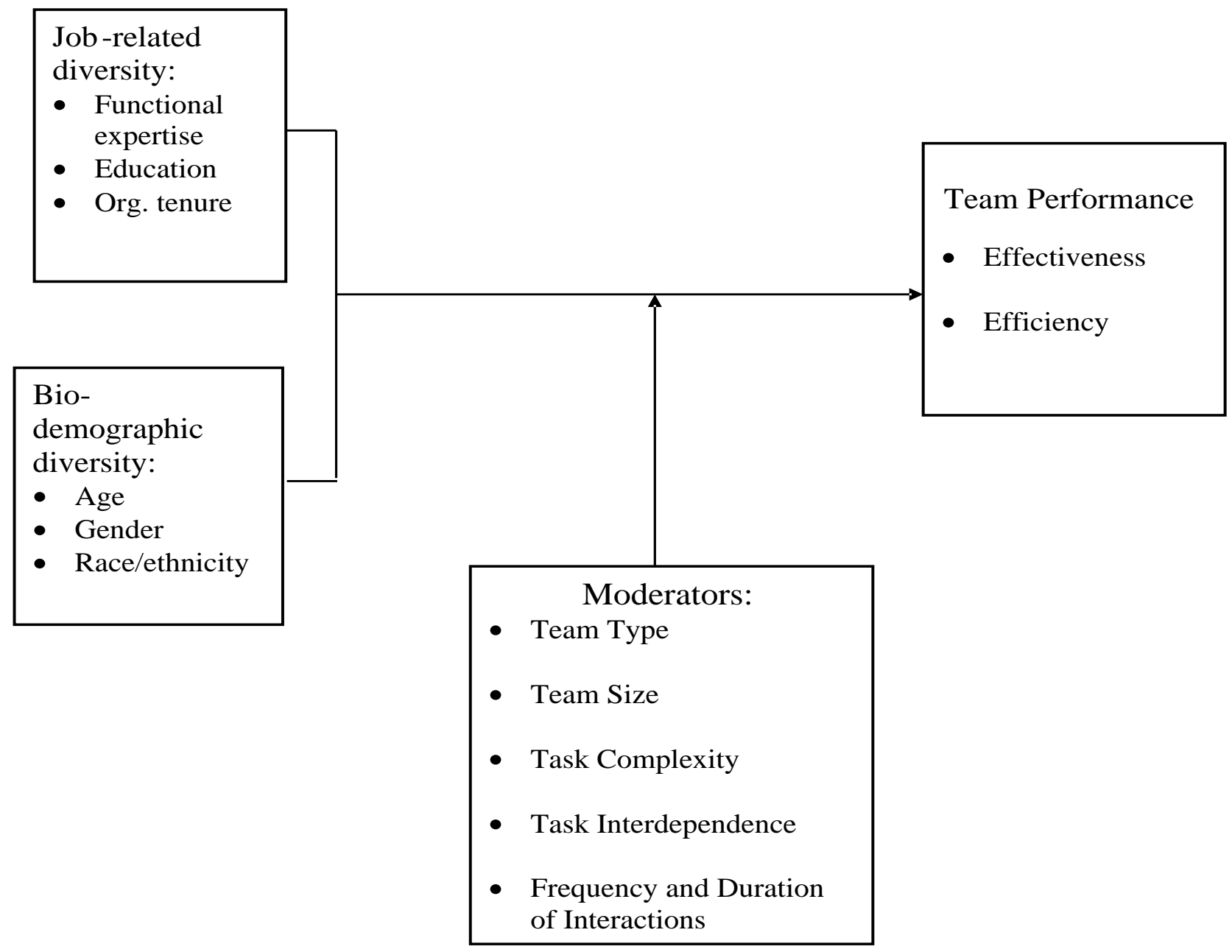

Figure I. An integrated model of social and information processing perspectives on workgroup diversity (Horwitz, 2005, p. 226). 


\section{How Well Does Research Reflect Diversity Outcomes?}

The foundational literature regarding diversity in the workforce is decidedly mixed. Theoretical assumptions assert that diversity in workgroups can have both positive and negative effects (Christian, Porter and Moffitt, 2006). While some researchers assert that there will be positive outcomes because of broader perspectives, other researchers assert that detrimental effects will accrue because of problems with group cohesion. Thus, the combined effects of the use of diversity in workgroups are not well defined (Milliken and Martins, 1996). However, the actual findings of the practical research in this area do not necessarily reflect this theoretical foundation. A comprehensive review of the literature demonstrates that there is a broad range of definitions of diversity in use in the literature, and that findings regarding the effects of diversity tend to vary based on the definition in use (Christian, Porter and Moffitt, 2006). According to the review of Christian, Porter and Moffitt (2006), most diversity research focuses on demographic attributes, including "age, gender, race-ethnicity, functional background, educational background, and tenure" ( $p$. 460). Although other forms of diversity are sometimes reviewed in the research, they tend to be much rarer. The empirical literature is also mixed on whether or not the expected improvements in organizational effectiveness actually occur, with many studies finding that a reduction in diversity actually increases group performance as well as cohesion (Christian, Porter and Moffitt, 2006).

\section{Methodology}

The methodology used in this research was a literature search and review methodology, in which various discussions of diversity management in the literature were selected and compared based on their definitions of diversity. The goal of the research was to determine what differences, if any, were made between social and functional diversity. Articles were selected using the number of citations found in database searches (indicating impact on existing literature). The articles that were selected were all field studies, surveys, or other empirical findings rather than theoretical studies (although theoretical studies often suffer from the same issues of lack of definition, as noted above). They were then compared according to their definitions of the terms and identification of differences between functional and social diversity. The goal was to determine the availability and clarity of differentiation between functional and social diversity in the literature, including both theoretical literature and empirical literature including case studies.

\section{Findings}

The findings were based on nine studies derived from the organizational literature of the past twenty years. All of these studies were field studies, surveys, or other empirical research studies aimed at identifying causes and understandings of diversity in the organization. These studies were selected because it is presumed that these field studies, offering empirical findings, would be considered to be most useful in a practical diversity management environment. Thus, they would be the most likely sources of information for human resources managers in organizations enacting the diversity programs. Table I summarizes the studies and provides a general overview of their methods and findings. 


\begin{tabular}{|c|c|c|c|}
\hline Author, Y ear & $\begin{array}{c}\text { Study M ethodology } \\
\text { and Topic }\end{array}$ & $\begin{array}{c}\text { Setting, Population } \\
\text { and Sample }\end{array}$ & Summary of Key Findings \\
\hline $\begin{array}{l}\text { Rynes and Rosen } \\
\text { (1995) }\end{array}$ & $\begin{array}{l}\text { Survey method } \\
\text { exploring diversity } \\
\text { issues within multiple } \\
\text { organizations, } \\
\text { especially focusing } \\
\text { on the success of } \\
\text { diversity training } \\
\text { programs }\end{array}$ & $\begin{array}{l}\text { Human resources } \\
\text { professionals from } \\
\text { A merican firms ( } n= \\
785 \text { ) }\end{array}$ & $\begin{array}{l}\text { The adoption of diversity } \\
\text { training was positively } \\
\text { statistically correlated with } \\
\text { top management support, } \\
\text { organizational size, and } \\
\text { prioritization of diversity } \\
\text { based objectives and staffing. } \\
\text { Thus, these factors were } \\
\text { associated with increased } \\
\text { likelihood of diversity } \\
\text { training adoption }\end{array}$ \\
\hline $\begin{array}{l}\text { Jehn, N orthcraft } \\
\text { and N eil (1999) }\end{array}$ & $\begin{array}{l}\text { Multi-method field } \\
\text { study intended to } \\
\text { identify major } \\
\text { impacts of different } \\
\text { types of diversity, } \\
\text { including social } \\
\text { category, value, and } \\
\text { information diversity }\end{array}$ & $\begin{array}{l}\text { W orkgroups in a } \\
\text { household moving } \\
\text { goods firm ( } n=92 \\
\text { groups, } 545 \\
\text { employees) }\end{array}$ & $\begin{array}{l}\text { Information and social } \\
\text { category diversity within the } \\
\text { workgroup had positive } \\
\text { outcomes (including } \\
\text { increased efficiency and } \\
\text { morale) but value diversity } \\
\text { negatively affected intention } \\
\text { to remain }\end{array}$ \\
\hline $\begin{array}{l}\text { Richard and } \\
\text { Kirby (1999) }\end{array}$ & $\begin{array}{l}\text { Laboratory study } \\
\text { designed to elicit } \\
\text { understanding of how } \\
\text { justification of } \\
\text { diversity programs } \\
\text { impacted acceptance } \\
\text { and performance of } \\
\text { diversity programs }\end{array}$ & $\begin{array}{l}\text { Upper-division } \\
\text { undergraduate } \\
\text { business students ( } \mathrm{n} \\
=93 \text { ) }\end{array}$ & $\begin{array}{l}\text { U se of organizational justice } \\
\text { as a justification for diversity } \\
\text { programs did improve hiring } \\
\text { outcomes (where } \\
\text { improvement was defined as } \\
\text { a degree of success in hiring } \\
\text { diverse candidates, but did } \\
\text { not address skill levels of } \\
\text { qualifications of candidates) } \\
\text { but did not improve actual } \\
\text { performance of these } \\
\text { programs }\end{array}$ \\
\hline $\begin{array}{l}\text { Bunderson and } \\
\text { Sutcliffe (2002) }\end{array}$ & $\begin{array}{l}\text { M ixed method } \\
\text { comparison of } \\
\text { different } \\
\text { conceptualizations of } \\
\text { functional diversity } \\
\text { within the literature } \\
\text { and their effects on } \\
\text { the outcomes }\end{array}$ & $\begin{array}{l}\text { W orkgroup sites } \\
\text { from a Fortune } 100 \\
\text { company ( } n=45 \\
\text { teams) }\end{array}$ & $\begin{array}{l}\text { The differentiation of } \\
\text { functional diversity between } \\
\text { dominant functional diversity } \\
\text { and intrapersonal functional } \\
\text { diversity had different effects } \\
\text { on information sharing and } \\
\text { performance. When } \\
\text { considering dominant } \\
\text { functional diversity, } \\
\text { information sharing and } \\
\text { performance was improved. } \\
\text { However, when considering } \\
\text { intrapersonal functional } \\
\text { diversity, information } \\
\text { sharing and performance was } \\
\text { negatively affected. }\end{array}$ \\
\hline
\end{tabular}




\begin{tabular}{|c|c|c|c|}
\hline $\begin{array}{l}\text { Zanoni and } \\
\text { Janssens (2004) }\end{array}$ & $\begin{array}{l}\text { Interviews with } \\
\text { human resource } \\
\text { managers in order to } \\
\text { determine discourses } \\
\text { surrounding diversity } \\
\text { in the organization }\end{array}$ & $\begin{array}{l}\text { Flemish human } \\
\text { resource } \\
\text { administrators ( } \mathrm{n}= \\
25 \text { ) }\end{array}$ & $\begin{array}{l}\text { Contrary to most } \\
\text { organizational studies } \\
\text { regarding the understandings } \\
\text { of diversity, discourses } \\
\text { provided by study } \\
\text { participants indicates that } \\
\text { power is a major component } \\
\text { in the definition of diversity } \\
\text { used in the organization by } \\
\text { active human resources } \\
\text { management professionals } \\
\text { and leaders. }\end{array}$ \\
\hline $\begin{array}{l}\text { Jehn and } \\
\text { B ezrukova (2004) }\end{array}$ & $\begin{array}{l}\text { Statistical analysis of } \\
\text { compensation levels } \\
\text { of workgroups based } \\
\text { on diversity factors }\end{array}$ & $\begin{array}{l}\text { Workgroups in a } \\
\text { Fortune } 500 \\
\text { information } \\
\text { processing firm ( } n= \\
1,528 \text { teams, with an } \\
\text { undisclosed number } \\
\text { of individual } \\
\text { employees) }\end{array}$ & 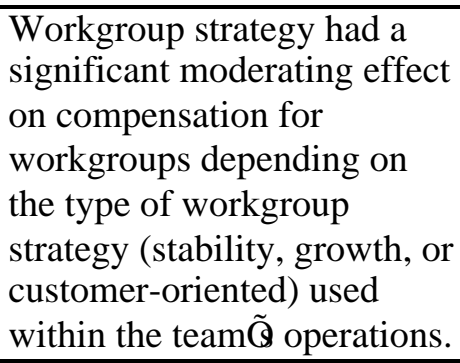 \\
\hline $\begin{array}{l}\text { Gonzales and } \\
\text { D enisi (2009) }\end{array}$ & $\begin{array}{l}\text { Statistical analysis at } \\
\text { the organizational } \\
\text { level to determine } \\
\text { demographic } \\
\text { diversity effects on } \\
\text { firm effectiveness }\end{array}$ & $\begin{array}{l}\text { Units of a national } \\
\text { restaurant chain }(\mathrm{n}= \\
28)\end{array}$ & $\begin{array}{l}\text { Diversity climate is found to } \\
\text { be key in the building of } \\
\text { positive organizational } \\
\text { identification }\end{array}$ \\
\hline $\begin{array}{l}\text { Pitts, Hicklin, } \\
\text { Hawes and } \\
\text { M elton (2010) }\end{array}$ & $\begin{array}{l}\text { M eta analysis of } \\
\text { existing survey data } \\
\text { in order to determine } \\
\text { drivers for adoption } \\
\text { of diversity } \\
\text { management } \\
\text { programs in public } \\
\text { administration }\end{array}$ & $\begin{array}{l}\text { Public school } \\
\text { superintendents in } \\
\text { Texas }(n=586)\end{array}$ & $\begin{array}{l}\text { Diversity management is } \\
\text { driven by environmental } \\
\text { favorability, institutional } \\
\text { isomorphism (social } \\
\text { similarity) and } \\
\text { environmental uncertainty, } \\
\text { but these efforts have } \\
\text { different effects }\end{array}$ \\
\hline $\begin{array}{l}\text { stergaard, } \\
\text { Timmermans, and } \\
\text { K ristinsson } \\
\text { (2011) }\end{array}$ & $\begin{array}{l}\text { Econometric analysis } \\
\text { of the relationship } \\
\text { between diversity and } \\
\text { innovation using two } \\
\text { linked surveys that } \\
\text { combined the } \\
\text { demographic } \\
\text { composition of the } \\
\text { firm and results of an } \\
\text { innovation study }\end{array}$ & $\begin{array}{l}\text { Danish firms with } \\
\text { more than } 20 \\
\text { employees }(n= \\
1775)\end{array}$ & $\begin{array}{l}\text { Study used social diversity } \\
\text { characteristics only, } \\
\text { including age, gender, } \\
\text { ethnicity, and education. } \\
\text { Education and gender were } \\
\text { positively associated with } \\
\text { innovation, age had a } \\
\text { negative association, and } \\
\text { ethnicity had no effect. }\end{array}$ \\
\hline
\end{tabular}

Table I Summary of studies examined 
The studies that were examined had a wide range of different definitions and understandings of diversity, with some focusing on functional diversity, some on social diversity, and some attempting to integrate both perspectives. In two cases the studies were unusual in their focus. The study by Gonzales and Denisi (2009) is the only study identified that had an organizational rather than a workgroup or team orientation. This was to be expected given the theoretical literature review, which indicated that the vast majority of such studies are based on the workgroup rather than on the organization as a whole (despite the grounding in organizational studies) (Van Knippenberg and Schippers, 2007). However, it was surprising that so few studies were selected that addressed this issue. The second unusual study was the study by Zanoni and Janssens (2004), which integrated the views of the human resources professionals identified into the study rather than focusing entirely on received definitions from academic literature. This finding was particularly important because of the introduction of the issue of social power, which is conspicuously absent from the rest of the literature on diversity.

Studies were examined in a number of different lights, with major themes being allowed to come to light through this multiple analysis. The main themes that were chosen for analysis in these studies included preciseness of definition of diversity and selection of diversity types and typologies. The implications of these definitions for the practice of diversity management are also discussed.

\section{Definition of Diversity}

Although the majority of studies offered a brief definition of diversity, not all offered a clear differentiation between functional and social diversity. Gonzales and Denisi (2009) identified diversity simply as "differences between individuals on any personal attributes that determine how people perceive one another" (p. 22). They did not differentiate between social and functional diversity, instead grouping all diversity traits into a single undefined category. One of the most limited definitions was offered by Richards and Kirby (1999), who defined diversity only as differences in a limited subset of demographic characteristics (including age, race-ethnicity, and gender).

A more expansive definition was offered by Jehn and Bezkrukova (2004), who, beginning with a generic definition of diversity similar to the one offered by
Gonzalez and Denisi (2009), further refined this definition using multiple guidelines. In particular, the authors clarified the issue of visibility of diversity, which was not well discussed within the majority of studies (Jehn and Bezrukova, 2004). This definition was one of the more comprehensive definitions that found within the research. However, the most comprehensive definition of diversity identified information diversity, social diversity, and value diversity as separate constructs and identified different factors in each of these constructs (Jehn, Northcraft and Neale, 1999). This definition is both the clearest and most useful in the study; unfortunately, it was not repeated. The definition of diversity offered by Zanoni and Janssens (2004) was among the most useful because it identified a definition actually in use in the organizations they studied. This definition also encompassed the idea of power and its relation to diversity, a factor that is noticeably missing from the formal academic definitions. Given the relative importance of power in the conflict between social identities, it seems clear that this would be a significant factor in the actual practice of diversity management in the organization. Thus, its lack in the formal definitions of the academic literature is significant.

Some researchers did not offer a definition of their core constructs at all, or defined them only obliquely. In particular, Rynes and Rosen (1995) discussed diversity training, but did not define either diversity or diversity training in their discussion. Bunderson and Sutcliffe (2002) focused on functional diversity, but did not define functional diversity as a general concept, referring instead to their two sub-constructs in their definition. Pitts, et al. (2010) also did not offer an underlying definition of diversity, although they did define the overarching construct of diversity management well. Østergaard, Timmermans and Kristinsson (20II) identified the various types of diversity studied, but did not provide an explicit definition (although they did discuss the issue of cognitive differences based on social diversity constructs). 


\section{Selection of Diversity Types and Typologies}

The choice of social or functional diversity (or both) varied between studies. Bunderson and Sutcliffe (2002) studied functional diversity, using two different formulations including dominant function diversity and intrapersonal functional diversity to compare different formulations of functional diversity. However, the authors did not specify how this type of diversity was defined. A common selection of social diversity types were race-ethnicity and gender (Gonzales and Denisi, 2009), although some studies focused only on a single aspect of diversity such as race (Richards and Kirby, 1999). Østergaard, Timmermans and Kristinsson (20II) also used ethnicity (although not classified as race) and gender, as well as age and educational level. Arguably, educational level could actually be seen as a functional characteristic, but this distinction was not made by the authors, who positioned education as a demographic difference. The authors did not use any other functional characteristics.

Some authors combined studies of both social and functional diversity, with varying degrees of differentiation between them. For example, Jehn and Bezrukova (2004) used a mixture of social characteristics (age, race and gender) and functional characteristics (tenure, educational level, and functional background) as differentiating factors, although they did not identify these groupings as social or functional. Jehn, Northcraft and Neal (1999), however, clearly identified multiple forms of diversity and identified which characteristics belonged to each, providing a very clear understanding of the constructs they were using.

A few researchers did not clearly identify the type of diversity they were discussing. For example, Rynes and Rosen (1995), who discussed diversity training programs, but did not examine what the content of these training programs was. Given the time period and the fact that they mentioned women and minorities in the introduction, it can be presumed that gender and race-ethnicity were the targets of the diversity training programs discussed, but this is not explicitly identified. There was no clear definition of the type of diversity discussed in Zanoni and Janssens (2004), but given the emergent nature of this research this is a reasonable outcome for this study. There was also no clear indication of a type of diversity focused on by Pitts, et al. (20l0).

\section{Implications of Definition}

The wide variance in definitions of diversity offered by the field studies and surveys in this research does have some important implications. The first implication is that, obviously, there is some degree of ambiguity even within the academic literature regarding the definition of diversity, as it often does not differentiate between social and functional diversity constructs. Although the model offered by Horwitz (2005) does provide an integrative model, none of the research used discussed this integrative model. Instead, there were a number of different models, which either focused on one or the other (the primary approach) or simply mashed together different types of characteristics. The only researchers that clearly identified different types of diversity were Jehn, Northcraft and Neal (1999), whose research hinged on the different types of diversity. Otherwise, there was a great deal of overlap between categories, and many of the studies failed to offer this definition at all. Given the confusion regarding these definitions in some of the most accessed literature, it is not surprising that there is a lack of clarity regarding the definition and understanding of diversity within the practice of diversity management. Clarification in this regard would be extremely important for improving outcomes.

A related issue, although it does not speak directly to the problem of differentiation in the academic literature, is a gap between practical and theoretical research in its understanding of the meaning of social diversity in the organization. Research focused on field definitions identifies power as a major factor in diversity within the organization, explicitly recognizing the power differentials inherent in social identity groups (Zanoni and Janssens, 2004). However, this acknowledgement is often missing in academic literature, with reasons why friction might arise between social identities being left unexplored. While this is certainly an uncomfortable question in many cases, as it is difficult to admit that power differentials continue to exist among social groups in the modern organization, it is certainly an issue that deserves further exploration. 


\section{Contribution to the Field}

The existing literature is often confusing on the difference between social diversity (which is neutral to unhelpful in the organization) and functional diversity (which is helpful in the organization). This can often lead to a feeling of disenchantment with diversity programs that do not seek to define the difference between these two concepts, but instead accepts all diversity as positive diversity. By offering a clear distinction between social diversity and functional diversity, this paper offers a contribution to the practice of diversity management by allowing for identification of specific traits of diversity and a better understanding of how diversity functions in the organization.

\section{Limitations}

The main limitation of this research is that, as it is based on prior research and synthesis, it cannot make exact statements about the pragmatic value of this clarification in the organization. It is suggested that applying this definition to clarify the goals and processes of an organization as a case study would be able to determine the value of its application within the organization.

\section{Conclusion}

After three decades of talking about diversity in the workplace there is still considerable confusion over what diversity actually consists of. Broad definitions seek inclusion, but do not allow for identification of a difference between functional and social diversity. Narrow definitions may be used to define either of these, but exclude a large number of diverse understandings. These differences often leave organizations in a state of confusion, as a diversity management program adopted in good faith falters or fails due to lack of consistency in the definition of diversity. To effectively manage diversity, it is necessary for organizations to understand the difference between functional and social diversity, and to treat these forms of diversity differently in terms of creating functional and innovative teams.

This research has shown that this issue is not clear even within the management literature or education literature, which does lead to some obvious problems in clarifying the definition of diversity for practice. Although this research has provided some clarification in terms of the alternative definitions, these definitions have only rarely been put into practice in the pragmatic research. This represents an ongoing gap in the research and an opportunity to dramatically improve the outcomes of diversity management in practice. The difference between social and functional diversity should be clearly emphasized within the literature and efforts should be made to explain what this difference means in practice for the organization. This will help to improve both expectations of diversity management programs and their outcomes.

\section{References}

BRICKSON, S. (2000). The impact of identity orientation on individual and organizational outcomes in demographically diverse settings. The Academy of Management Review, 25(I), 82-10I.

BUNDERSON, J. S., Sutcliffe, K. M. (2002). Comparing alternative conceptualizations of functional diversity in management teams. The Academy of Management Journal, 45(5), 875-893.

CHRISTIAN, J., Porter, L. W., Moffitt, G. (2006). Workplace diversity and group relations: An overview. Group Processes \& Intergroup Relations, 9(4), 459-466.

COX, T. H., Blake, S. (199I). Managing cultural diversity: Implications for organizational competitiveness. Executive, 5(3), 45-56.

FRIEDRICH, T. L., Mumford, M. D., Vessey, B., Beeler, C. K., Eubanks, D. L. (2010). Leading for innovation: Reevaluating leader influences on innovation with regard to innovation type and complexity. International Studies of Management \& Organization, 40(2), 6-29.

GONZALES, J. A., Denisi, A. S. (2009). Crosslevel effects of demography and diversity climate on organizational attachment and firm effectiveness. Journal of Organizational Behavior, 30(I), 2I-40.

GUZZO, R. A., Dickson, M. W. (1996). Teams in organizations: Recent research on performance and effectiveness. Annual Review of Psychology, 47(I), 307-338.

HORWITZ, S. K. (2005). The compositional impact of team diversity on performance: Theoretical considerations. Human Resource Development Review, 4(2), 219-245. 
JEHN, K. A., Bezrukova, K. (2004). A field study of group diversity, workgroup context, and performance. Journal of Organizational Behavior, 25(6), 703-729.

JEHN, K. A., Northcraft, G. B., Neale, M. A. (1999). Why differences make a difference: A field study of diversity, conflict, and performance in workgroups. Administrative Science Quarterly, 44(4), 74I-763.

MCPHERSON, M., Smith-Lovin, L., Cook, J. M. (200I). Birds of a feather: Homophily in social networks. Annual Review of Sociology, 27(I), 4I5-444.

MILLIKEN, F.J., Martins, L. L. (1996). Searching for common threads: Understanding the multiple effects of diversity in organizational groups. Academy of Management Review, 2I(2), 402-433.

ØSTERGAARD, C. R., Timmermans, B., Kristinsson, K. (20II). Does a different view create something new? The effect of employee diversity on innovation. Research Policy, 40(3), 500-509.

PITTS, D. W., Hicklin, A. K., Hawes, D. P., Melton, E. (2010). What drives the implementation of diversity management programs? Evidence from public organizations. Journal of Public Administration Research \& Theory, 20(4), 867-886.

RICHARDS, O. C., Kirby, S. L. (1999). Organizational justice and the justification of work force diversity programs. Journal of Business \& Psychology, I4(I), 109-II8.

RYNES, S., Rosen, B. (1995). A field survey of factors affecting the adoption and perceived success of diversity training. Personnel Psychology, 48(2), 247-270.

SCHNEIDER, S. K., Northcraft, G. B. (1999). Three social dilemmas of workforce diversity in organizations: A social identity perspective. Human Relations, 52(II), I445-1467. VAN KNIPPENBERG, D., Schippers, M. C. (2007). Work group diversity. Annual Review of Psychology, 58(I), 515541.

ZANONI, P., Janssens, M. (2004). Deconstructing difference: The rhetoric of human resource managers' diversity discourses. Organizatio 
J. Technol. Manag. Innov. 20II,Volume 6, Issue 3 